Check for updates

Cite this: RSC Adv., 2017, 7, 27206

Received 14th March 2017

Accepted 16th May 2017

DOI: $10.1039 / c 7 r a 03042 h$

rsc.li/rsc-advances

\section{Glibenclamide-sulfonylurea receptor 1 antagonist alleviates LPS-induced BV2 cell activation through the p38/MAPK pathway $\dagger$}

\author{
Zhiming Xu, (D) $\dagger^{a}$ Yingliang Liu,,$^{\mathrm{a}}$ Dianxu Yang, ${ }^{\mathrm{a}}$ Fang Yuan, ${ }^{\mathrm{a}} \mathrm{Jun}$ Ding, ${ }^{\mathrm{a}}$ Liping Wang, ${ }^{\mathrm{b}}$ \\ Meijie Qu, ${ }^{b}$ Guoyuan Yang ${ }^{\text {bc }}$ and Hengli Tian ${ }^{\star a}$
}

\begin{abstract}
We investigated the anti-neuroinflammatory activity and mechanism of glibenclamide, sulfonylurea receptor 1 (Sur1) antagonist, against LPS-induced microglial activation in vitro. BV2 microglia cells were exposed to LPS (100 ng mL ${ }^{-1}$ ). iNOS and COX-2 levels, proinflammatory cytokine mRNA expression, and the p38/MAPK signaling pathway were analyzed by RT-PCR and Western blotting. Pretreatment with glibenclamide $(2.5,10$, and $40 \mu \mathrm{M})$ inhibited the LPS-induced overexpression of iNOS and COX-2 in BV2 microglia cells. Blocking Sur1 reduced intracellular reactive oxygen species (ROS) levels. Glibenclamide dose-dependently $(2.5,10 \mu \mathrm{M})$ decreased LPS-induced over-expression of TNF- $\alpha, \mathrm{IL}-6$, and IL-1 $\beta$, and alleviated the intracellular calcium accumulation in LPS-treated BV2 microglia cells. Moreover, glibenclamide diminished the LPS-induced phosphorylation of p38/MAPK, SB203580, a selective p38/ MAPK inhibitor, significantly potentiated glibenclamide-caused inhibition of the expression of iNOS and COX-2 in LPS-exposed BV2 cells. Glibenclamide-Sur1 antagonist exerts anti-inflammatory activity in murine microglia in vitro by inhibiting the p38/MAPK signaling pathways and proinflammatory responses. Glibenclamide may be developed as a novel agent for suppressing inflammatory responses in the central nervous system.
\end{abstract}

\section{Introduction}

Sulfonylurea receptor 1 (Sur1), a member of the ATP-binding cassette (ABC) superfamily, is best known for its role in KATP channels. ${ }^{1,2}$ Two nucleotide-binding folds contained in Sur1 provide its high affinity for therapeutic sulfonylurea drugs. More recently, Sur1 has also been found to have a role in the formation of Sur1-regulated NCCa-ATP channels. $^{3}$ Sur1regulated channel activity can be strongly inhibited by drugs, such as glibenclamide (glyburide) and repaglinide. Previous studies have shown that this receptor is involved in cerebral ischemia, ${ }^{3}$ subarachnoid hemorrhage $(\mathrm{SAH}),{ }^{4}$ spinal cord injury, ${ }^{5}$ traumatic brain injury (TBI), ${ }^{6}$ multiple sclerosis (MS), ${ }^{7}$ intestinal ischemia and reperfusion injury, ${ }^{8}$ and many pathophysiological processes. Previous studies have suggested that Sur1 was associated with cerebral edema, including central nervous system (CNS) impairment induced cerebral edema and cerebral edema caused by hepatic encephalopathy ${ }^{9}$ and cerebral

\footnotetext{
${ }^{a}$ Department of Neurosurgery, Shanghai Jiao Tong University Affiliated Sixth People's Hospital, Shanghai, China. E-mail: tianhlsh@126.com

${ }^{b}$ Department of Neurology, Ruijin Hospital, Shanghai Jiao Tong University School of Medicine, Shanghai, China

${ }^{c}$ Neuroscience and Neuroengineering Research Center, Med-X Research, Shanghai Jiao Tong University, Shanghai, China

$\dagger$ These authors have contributed equally to this work.
}

edema caused by hepatic encephalopathy. ${ }^{10}$ It has also been shown that Sur1 played a role in blood-brain tumor barrier permeability, as permeability of the barrier decreased significantly after blocking the receptor. ${ }^{11}$

Increasing numbers of studies have found that the CNS inflammation has a key role in ischemic brain injury, TBI, Alzheimer's disease, and Parkinson's disease (PD). ${ }^{12}$ Microglial activation is an important part of inflammation, which can impair neuronal survival and blood-brain barrier (BBB) integrity by generating oxidative stress and cytokines. ${ }^{13}$ Thus, the activation of microglia has important theoretical and therapeutic significance. To date, although studies have suggested that the Sur1 is related to the inflammatory response after stroke and that the receptor blocker glibenclamide can alleviate inflammation in brain tissue after ischemia, there is no reported study regarding the role of Sur1, if any, in the activation of microglia. ${ }^{14}$ Thus, there is an important need to clarify the role of Sur1 in microglial activation and to examine the biological effects of Sur1 inhibitors on microglia.

Glibenclamide, known as glyburide in the US, is a widely prescribed drug that has been used for the treatment of diabetes mellitus type 2 (DM II) since the $1960 \mathrm{~s} .{ }^{15}$ Glibenclamide binds to sulfonylurea receptors and stimulates the closure of adenosine triphosphate (ATP)-sensitive potassium channels, which, in turn, encourages the secretion of insulin from pancreatic $\beta$-cells. As a member of the sulfonylurea class of 
drugs, glibenclamide inhibits sulfonylurea receptor 1 (Sur1) and KATP (Sur1-Kir6.2) channels on $\beta$ cells in the pancreatic islet. This leads to enhanced insulin release, which is beneficial for patients with DM II. ${ }^{16-19}$ Laboratory investigations have also shown that subjects with various CNS pathologies, including focal cerebral ischemia, ${ }^{3}$ neonatal encephalopathy due to prematurity, ${ }^{20}$ and metastatic brain tumors, ${ }^{21}$ benefit from the administration of glibenclamide.

In this study, we used microglial BV2 cells as a cellular model to determine the effects of glibenclamide on microglial activation. Our study suggests that glibenclamide can profoundly affect the activation levels of the cells.

\section{Experimental section}

\section{Reagents}

Glibenclamide (Sigma-Aldrich, St. Louis, MO, USA) was dissolved in water containing $25 \%$ Cremophor EL (Sigma-Aldrich) and $10 \%$ dimethyl sulfoxide (DMSO; Sigma-Aldrich) diluted in culture medium before use (the concentration of DMSO was < $0.001 \%$ after dilution). LPS was purchased from Sigma-Aldrich. SB203580 (a p38/MAPK pathway-specific inhibitor) was purchased from Cell Signaling Technology (Danvers, MA, USA).

\section{Lactate dehydrogenase (LDH) assay}

BV2 cells were lysed for $20 \mathrm{~min}$ in lysing buffer $(0.04 \%$ Triton-X, $2 \mathrm{mM}$ HEPES, $0.2 \mathrm{mM}$ dithiothreitol, $0.01 \%$ bovine serum albumin, and $0.1 \%$ phenol red, pH 7.5). Cell lysates $(50 \mu \mathrm{L})$ were mixed with $150 \mu \mathrm{L} 500 \mathrm{mM}$ potassium phosphate buffer (pH 7.5) containing $1.5 \mathrm{mM} \mathrm{NADH}$ and $7.5 \mathrm{mM}$ sodium pyruvate, and the A340-nm change was monitored over $90 \mathrm{~s}$ with a spectrophotometer (BioTek, Winooski, VT, USA).

\section{Cell culture}

The BV2 microglia cell line was obtained from the Institute of Neurology, Ruijin Hospital (Shanghai, China) and maintained in Dulbecco's Modified Eagle's Medium (DMEM; Gibco Laboratories; Grand Island, NY, USA), supplemented with 5\% fetal bovine serum (FBS), $100 \mu \mathrm{g} \mathrm{mL}^{-1}$ streptomycin, and $100 \mu \mathrm{g}$ $\mathrm{mL}^{-1}$ penicillin. Cultures were then transferred to an anaerobic chamber and infused with a gas mixture containing $5 \% \mathrm{CO}_{2}$ and $95 \% \mathrm{~N}_{2}$.

\section{Pharmacological treatment}

At $24 \mathrm{~h}$ after seeding, the cells were exposed to LPS (100 ng $\left.\mathrm{mL}^{-1}\right)$. The Sur1 antagonist glibenclamide $(2.5,10,40 \mu \mathrm{M})$ and SB203580 $(10 \mu \mathrm{M})$ were added to the medium $1 \mathrm{~h}$ before exposure to LPS until the end of the experiments.

\section{Measurement of reactive oxygen species (ROS) levels}

Intracellular reactive oxygen species (ROS) levels were monitored using a fluorescent probe with dihydroethidium (DHE; Beyotime, China). Ethidium can be combined with RNA or DNA to produce a red fluorescence. Under the condition of high level of intracellular superoxide anion, ethidium would exhibit strong red fluorescence. BV2 cells treated in 96-well plates were incubated with fresh working solution containing $5 \mathrm{mM}$ DHE in PBS for $30 \mathrm{~min}$ in an anaerobic chamber. Then, the cells were washed twice with ice-cold PBS, and subsequently visualized using a Leica (Germany) inverted fluorescence microscope. The red fluorescence intensities were quantitated by ELISA plate reader (BioTek, Winooski, VT, USA).

\section{Real-time PCR}

Total RNA samples from BV2 cells were extracted using the TRIzol reagent (Invitrogen, Carlsbad, CA, USA) and reversetranscribed to cDNA using a PrimeScript RT reagent kit (TaKaRa). The cDNA was amplified by PCR using the specific primers in Table 1. Quantitative real-time PCR was performed with an ABI 7900HT by using SYBR Premix Ex Taq (TaKaRa). Data were analyzed by using the comparative threshold cycle (Ct) method, results are expressed as fold differences, normalized to GAPDH.

\section{Determination of intracellular free calcium ion concentrations}

To determine the intracellular free $\mathrm{Ca}^{2+}$ concentration levels in BV2 cells, Fluo-3 AM (1-5 mmol L ${ }^{-1}$ ) was used. BV2 cells were pre-incubated with glibenclamide $(2.5,10$, and $40 \mu \mathrm{M})$ for $1 \mathrm{~h}$, then stimulated with $100 \mathrm{ng} \mathrm{mL}^{-1}$ LPS for a $24 \mathrm{~h}$ incubation period. Cells were washed with HBSS three times and then loaded with Fluo-3 AM for 10-60 min. Fluo-3 AM immunofluorescent intensity was quantified by ELISA plate reader (BioTek, Winooski, VT, USA).

\section{Western blot analysis}

For Western blot analyses, samples were lysed in radioimmunoprecipitation assay (RIPA; Millipore, Bedford, MA, USA) supplemented with $1 \mathrm{mmol} \mathrm{L}^{-1}$ PMSF (Thermo; Waltham, MA, USA), a protease inhibitor cocktail (Thermo), and a phosphatase inhibitor (Thermo). After denaturing, the same amount of proteins were loaded onto the resolving gel (Promoton; Shanghai, China) for electrophoresis and the proteins were transferred onto a nitrocellulose membrane (Whatman; Piscataway, NJ, USA). After blocking with 5\% non-fat milk, the membranes were incubated with primary antibodies overnight at $4{ }^{\circ} \mathrm{C}$ at the following dilutions: p-ERK1/2, ERK1/2, p-JNK, JNK,

Table 1 PCR primers

\begin{tabular}{ll}
\hline Gene target & Primer sequence \\
\hline iNOS & F: CCTTGGTGAAGGGACTGAGC \\
& R: CAACGTTCTCCGTTCTCTTGC \\
IL-1 $\beta$ & F: GCAACTGTTCCTGAACTCAACT \\
& R: ATCTTTTGGGGCGTCAACT \\
IL-6 & F: TCTATACCACTTCACAAGTCGGA \\
& R: GAATTGCCATTGCACAACTCTTT \\
TNF- $\alpha$ & F: GGAACACGTCGTGGGATAATG \\
& R: GGCAGACTTTGGATGCTTCTT \\
GAPDH & F: AGGTCGGTGTGAACGGATTTG \\
& R: TGTAGACCATGTAGTTGAGGTCA
\end{tabular}


p-p38, p38, and COX-2 (1:1000; Cell Signaling Technology), iNOS (1:10 000; Proteintech Group, Rosemont, IL, USA); Sur1 (1:1000; Abcam, Cambridge, MA, USA); and $\beta$-tubulin, and $\beta$ actin (1:1000, Santa Cruz Technology; Santa Cruz, CA, USA). After washing, the membranes were incubated with appropriate horseradish peroxidase (HRP)-conjugated secondary antibodies for $1 \mathrm{~h}$ at room temperature and then reacted with an enhanced chemiluminescence substrate (Pierce; Rockford, IL, USA). The results were recorded using the Quantity One imaging software (Bio-Rad; Hercules, CA, USA), and relative intensities were calculated with the Gel-Pro Analyzer software (Media Cybernetics; Bethesda, MD, USA).

\section{Statistical analysis}

All results were presented as mean \pm SD. Student's $t$ test was used for comparison between the two groups. $P<0.05$ was considered statistically significant. All data analyses were performed with SPSS 20.0 (SPSS Inc., Chicago, IL), GraphPad Prism 6 software (GraphPad Software; San Diego, CA) was used to create graphic representations of the data.

\section{Results and discussion}

To study the role of Sur1 in the development of cellular activation, we analyzed the expression of Sur1 protein in LPS-induced BV2 microglial cells. Protein samples were collected at $24 \mathrm{~h}$ after after LPS treatment, expression of Sur1 significantly increased compared with control group (Fig. 1B and C). In order to confirm whether glibenclamide could acted as a neuroinflammatory modulator, we used the BV2 microglial cell line as a model in vitro. First, we assessed its cytotoxicity to BV2 cells after a $24 \mathrm{~h}$ incubation with three different concentrations of glibenclamide. As shown in Fig. 1, the cell viability following treatment with $2.5,10$, and $40 \mu \mathrm{M}$ of glibenclamide did not significantly differ from that of the control. Proinflammatory cytokines, such as TNF- $\alpha$, IL-1 $\beta$, and IL-6, play central roles in microglia-mediated inflammation. Thus, the effects of glibenclamide on these proinflammatory cytokines were analyzed. BV2 cells were incubated with glibenclamide $(2.5,10$, and $40 \mu \mathrm{M})$ from $1 \mathrm{~h}$ before exposure to LPS (100 ng $\mathrm{mL}^{-1}$ ) until the end of the experiment. RT-PCR results demonstrated that the mRNA levels of these cytokines were elevated $6 \mathrm{~h}$ after LPS treatment. Pre-treatment with glibenclamide significantly inhibited LPS-induced iNOS, TNF- $\alpha$, IL-1 $\beta$, and IL-6 production versus the LPS-treated cells (Fig. 2). Statistical analysis showed that LPS-stimulated proinflammatory cytokine mRNA levels (iNOS, TNF- $\alpha$, IL-1 $\beta$, and IL-6) decreased significantly following glibenclamide treatment (Fig. 2A-D; $P<$ 0.05 and $P<0.01$, vs. the LPS group). Thus, these results indicated that glibenclamide inhibited the expression of cytokines involved in the inflammatory process. At the concentrations indicated $(2.5,10$, and $40 \mu \mathrm{M})$, glibenclamide significantly attenuated LPS-induced proinflammatory cytokines (TNF- $\alpha$, IL$1 \beta$, and IL-6) levels compared with LPS-treated cells (Fig. 2). Furthermore, we detected protein levels of iNOS and COX-2 by Western blotting. iNOS and COX-2 protein levels increased significantly in LPS-exposed BV2 cells compared with the controls (Fig. 3A and B, $P<0.01$, vs. the LPS group). Pre-

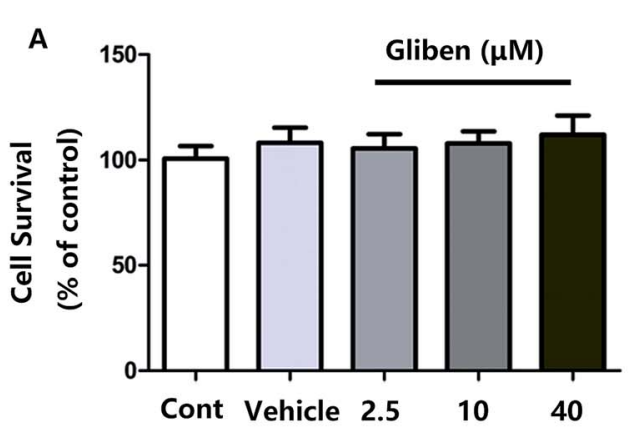

B

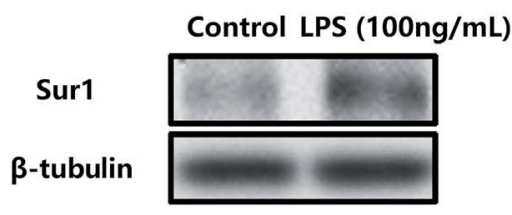

C

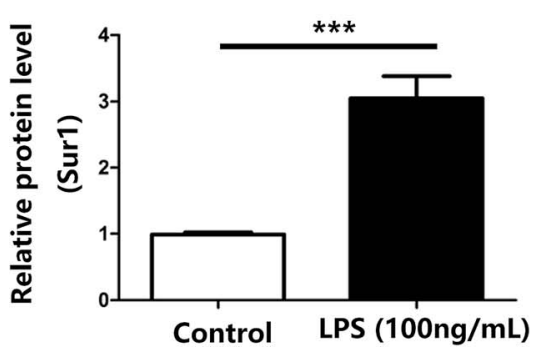

Fig. 1 Effect of glibenclamide on the cell viability of BV2 microglia, and Sur1 protein expression in LPS-exposed BV2 cells. Cells were treated with indicated concentrations of glibenclamide for a $24 \mathrm{~h}$ incubation period. Cell viability was assessed by LDH assay (A). BV2 cells were exposed to LPS (100 $\mathrm{ng} \mathrm{mL}^{-1}$ ), and Sur1 protein expression was measured $24 \mathrm{~h}$ later (B). A significant increase in Sur1 protein expression was observed following treatment with LPS $\left(100 \mathrm{ng} \mathrm{mL}^{-1}\right)$ versus the control condition (C). Data were subjected to two-sample Student's $t$-test. ***P< 0.001 , vs. control (Cont). Error bars, mean $\pm \mathrm{SE}$. 

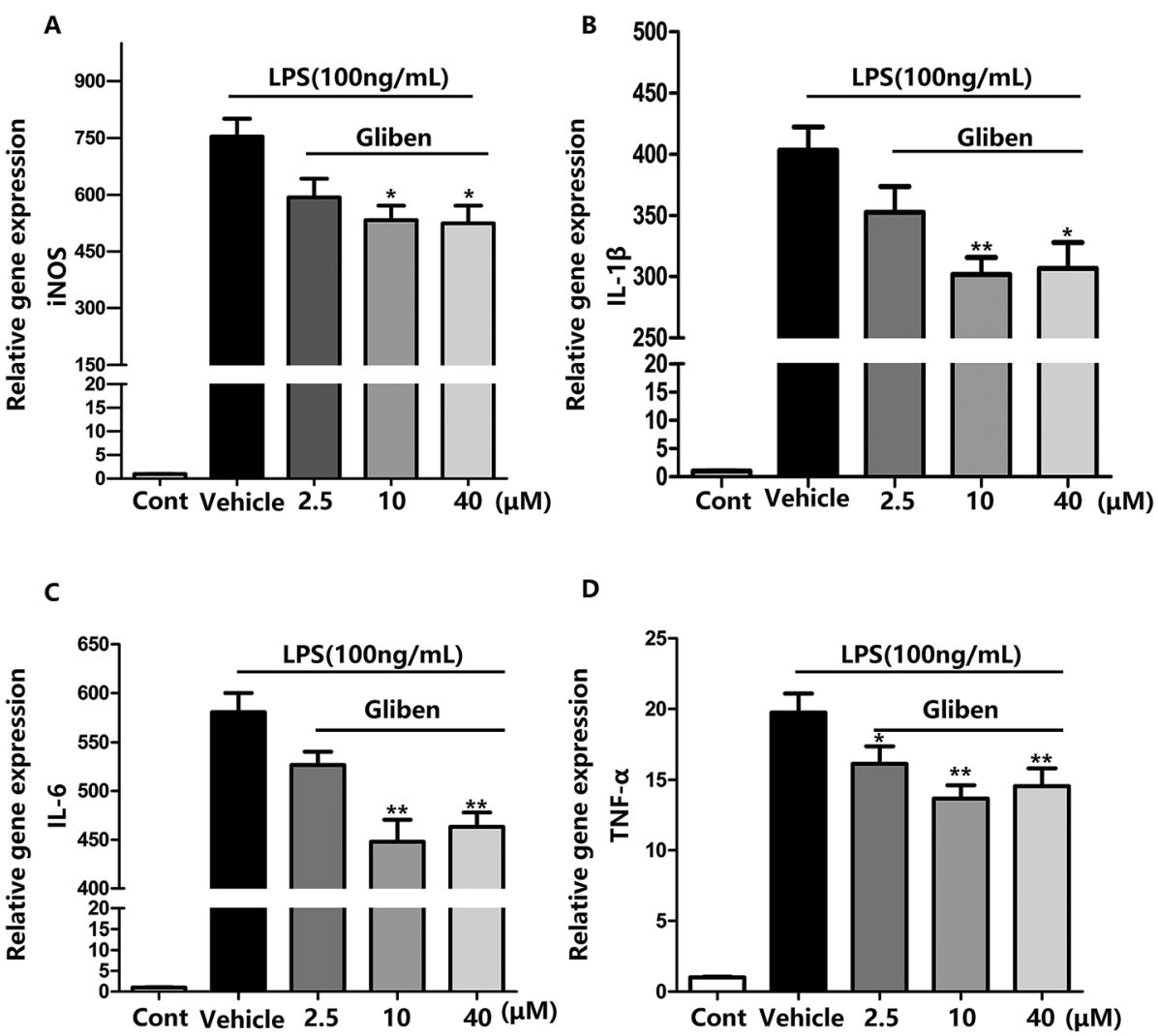

Fig. 2 Blocking Sur1 suppressed expression of iNOS, TNF- $\alpha$, IL-1 , and IL- 6 in BV2 cells. BV2 microglial cells were incubated with glibenclamide (Gliben, 2.5, 10, $40 \mu \mathrm{M}$ ) or vehicle for $1 \mathrm{~h}$ and were then stimulated with LPS (100 ng mL ${ }^{-1}$ ). After $6 \mathrm{~h}$, mRNA levels of iNOS (A), IL-1 3 (B), IL-6 (C), and TNF- $\alpha(D)$ were assessed by real-time PCR. Values represent the mean \pm SEM from at least three independent experiments. Control was abbreviated as Cont. Cont $* P<0.05$, vs. LPS alone, $* * P<0.01$, vs. LPS alone.

treatment with glibenclamide at various concentrations $(2.5,10$, and $40 \mu \mathrm{M}$ ) reduced the LPS-stimulated increase in iNOS and COX-2 levels significantly (Fig. 3A and B; $P<0.01$, vs. the LPS group). Western blot analysis showed that glibenclamide at 2.5 and $10 \mu \mathrm{M}$ inhibited iNOS and COX-2 levels in a dosedependent manner, whereas $40 \mu \mathrm{M}$ glibenclamide did not show a stronger inhibitory effect $(P<0.01, v s$. the control group).

Increased oxidative stress induces excessive ROS that can directly inflict DNA damage and activate cellular signaling pathways. ${ }^{22}$ Pre-treatment with glibenclamide $(2.5,10$, and 40 $\mu \mathrm{M})$ restrained ROS levels induced by LPS in BV2 cells. Dihydroethidium (DHE) was used to detect intracellular superoxide anion levels. Glibenglamide at 2.5 and $10 \mu \mathrm{M}$ of glibenclamide decreased ROS levels in a dose-dependent manner (Fig. 3C and D); 10 and $40 \mu \mathrm{M}$ glibenclamide had significantly different effects on levels of ROS.

Pretreatment with $100 \mathrm{ng} \mathrm{mL}^{-1}$ LPS elevated $\mathrm{Ca}^{2+}$ levels in BV cells .All three concentrations of glibenclamide reduced intracellular $\mathrm{Ca}^{2+}$ concentrations, although $40 \mu \mathrm{M}$ glibenclamide was not more effective than $10 \mu \mathrm{M}$ (Fig. 4C).

p38/MAPK pathway components, including ERK1/2, JNK, and $\mathrm{p} 38$, are phosphorylated in various stress responses. ${ }^{23}$ The phosphorylation of p38/MAPK induces the expression of proinflammatory molecules and is one of the most important signaling pathways in the inflammation response. ${ }^{24}$
Consequently, we used Western blotting to assess the effects of glibenclamide on stress-mediated cellular p38/MAPK signaling pathways after incubating BV2 cells with LPS for $24 \mathrm{~h}$. Glibenclamide at different concentrations $(2.5,10$, and $40 \mu \mathrm{M})$ suppressed LPS-induced phosphorylation of ERK1/2, p38, and JNK (Fig. 4). This finding suggested that glibenclamide was capable of modulating the p38/MAPK pathway which was activated by LPS treatment and decreasing the production of proinflammatory mediators.

We showed that LPS exposure increased p38/MAPK phosphorylation, and this induction was decreased after glibenclamide treatment (Fig. 3C and D). To further explore the mechanism(s) of glibenclamide in neuroinflammation, we analyzed iNOS and COX-2 levels. To determine whether glibenclamide-induced downregulation of iNOS and COX-2 was p38/MAPK-dependent, we analyzed the effect of glibenclamide at the cellular level, using LPS-induced BV2 cell activation to mimic in vivo neuroinflammation. In previous tests, we showed that different concentrations of glibenclamide $(2.5,10$, and 40 $\mu \mathrm{M})$ could reduce LPS-induced iNOS and COX-2 overexpression in BV2 cells; $10 \mu \mathrm{M}$ glibenclamide showed the maximum inhibitory effect ( $40 \mu \mathrm{M}$ did not show a greater effect).

MAPKs, including p38, JNK, and ERK1/2, which could be activated by LPS, are an important kinase family involved in various cellular processes, such as apoptosis, differentiation, 
A

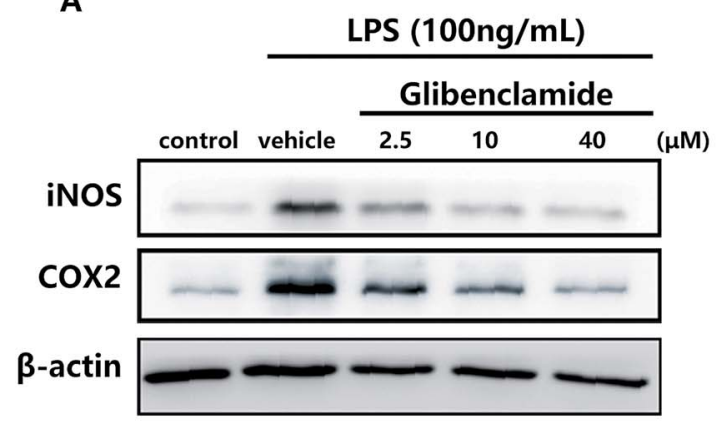

C

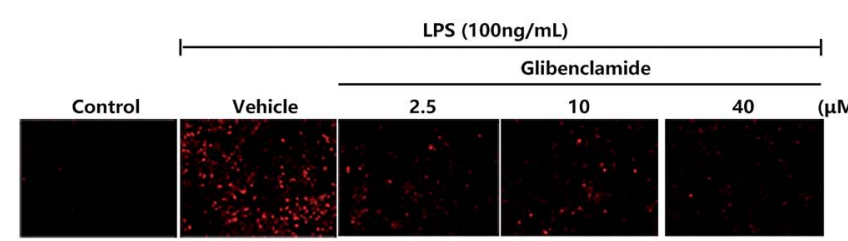

B

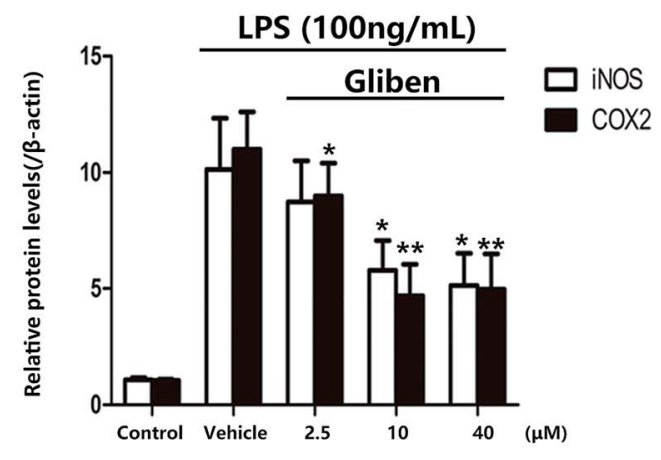

D

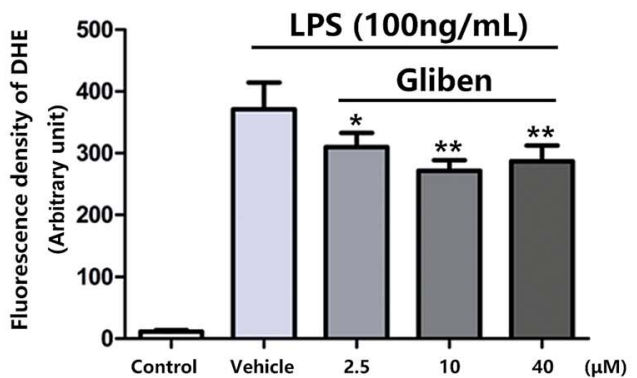

Fig. 3 The oxidative stress-induced inflammation in LPS-exposed BV2 cells were reduced by blocking Sur1. Levels of the inflammatory proteins iNOS and COX-2 (A) in LPS-exposed BV2 cells, pretreated with glibenclamide $(2.5,10$, and $40 \mu \mathrm{M})$ and vehicle, were determined by Western blot analysis (B). $\beta$-Actin was used as a control. BV2 cells were pretreated with glibenclamide (Gliben, 2.5, 10, and $40 \mu \mathrm{M}$ ) or vehicle and exposed to $100 \mathrm{mg} \mathrm{mL}^{-1}$ LPS for $24 \mathrm{~h}$. Intracellular ROS production was (C) visualized with the fluorescent dye, DHE was detected by fluorescence microscopy, and fluorescence intensity was quantified with a spectrophotometer (D). $* P<0.05$, vs. cells treated with only LPS alone.

stress responses and immune defense. ${ }^{25}$ This kinase family modulates cytokine production and expression of proinflammatory enzymes, such as NF- $\kappa \mathrm{B}$, iNOS, COX-2 and IL$1 \beta .^{26,27}$ Therefore, MAPKs are crucial elements in the inflammatory process and essential targets for anti-inflammatory molecules. We found that pretreatment with glibenclamide reduced upregulation of phospho-p38, phospho-ERK1/2 and phospho-JNK in activated BV2 cells. Thus, MAPKs may involve in the protective effects of glibenclamide in activated BV2 cells. Previous studies reported that attenuating phosphorylation of p38 MAPK relieved the level of microglia activation, ${ }^{28}$ phosphoERK and phospho-JNK is predominantly localized to astrocytes or neurons, and minimally localized to microglia cells in the spinal cord injury, however. ${ }^{29,30}$

To assess whether the p38/MAPK signaling pathway was involved, a selective p38/MAPK inhibitor, SB203580, was used. The effects of glibenclamide on the inhibition of iNOS and COX2 expression were consistent with the effect of a specific p38/ MAPK inhibitor SB203580 when examined simultaneously in LPS-stimulated BV2 cells (Fig. 5, $P<0.01$, vs. the LPS group). Furthermore, the effect of glibenclamide on the inhibition of iNOS and COX-2 was consistent with the effect SB203580 when examined simultaneously in LPS-stimulated BV2 cells. Experiments were also carried out and indicated that the SB203580 alone decreased LPS-induced iNOS and COX-2 overepression on
BV2 cells (Fig. 5, $P<0.01, P<0.01$, vs. the LPS group). Thus, we concluded that glibenclamide diminished neuroinflammation via the p38/MAPK signaling pathway.

In the present study, we demonstrated that glibenclamide, ATP-sensitive potassium channel (KATP) blocker, and a firstline sulfonylurea pharmacotherapy option for the treatment of DM II, ${ }^{31}$ has a significant inhibitory effect against inflammation, blocking the synthesis of a proinflammatory intermediary in LPS-stimulated BV2 microglia cells. A growing body of evidence suggests that neuroinflammation plays a pivotal role in numerous processes, such as TBI, ischemia, MS, SAH. ${ }^{32}$ Microglial activation is a key process in the propagation of inflammation to neighboring tissue, which may lead to neuronal impairment in the surrounding area as well as BBB damage as a result of the generation of cytokines and ROS. ${ }^{13,33,34}$ Activated BV2 microglia cells, induced by lipopolysaccharide (LPS) in an in vitro environment, provide a good model to study neuroinflammation. ${ }^{35}$ Neurotoxic molecules, such as iNOS, and COX-2, and cytokines, such as TNF- $\alpha$, IL-1 $\beta$, and IL-6 are synthesized and liberated during microglial activation. ${ }^{36,37}$ Because of the protective role of glibenclamide in CNS pathophysiological, glibenclamide was investigated further for its effects on iNOS and COX-2 expression and its effect on the release of proinflammatory cytokines. We observed that glibenclamide reduced the mRNA levels of TNF- $\alpha$, IL-1 $\beta$, and IL- 6 , 

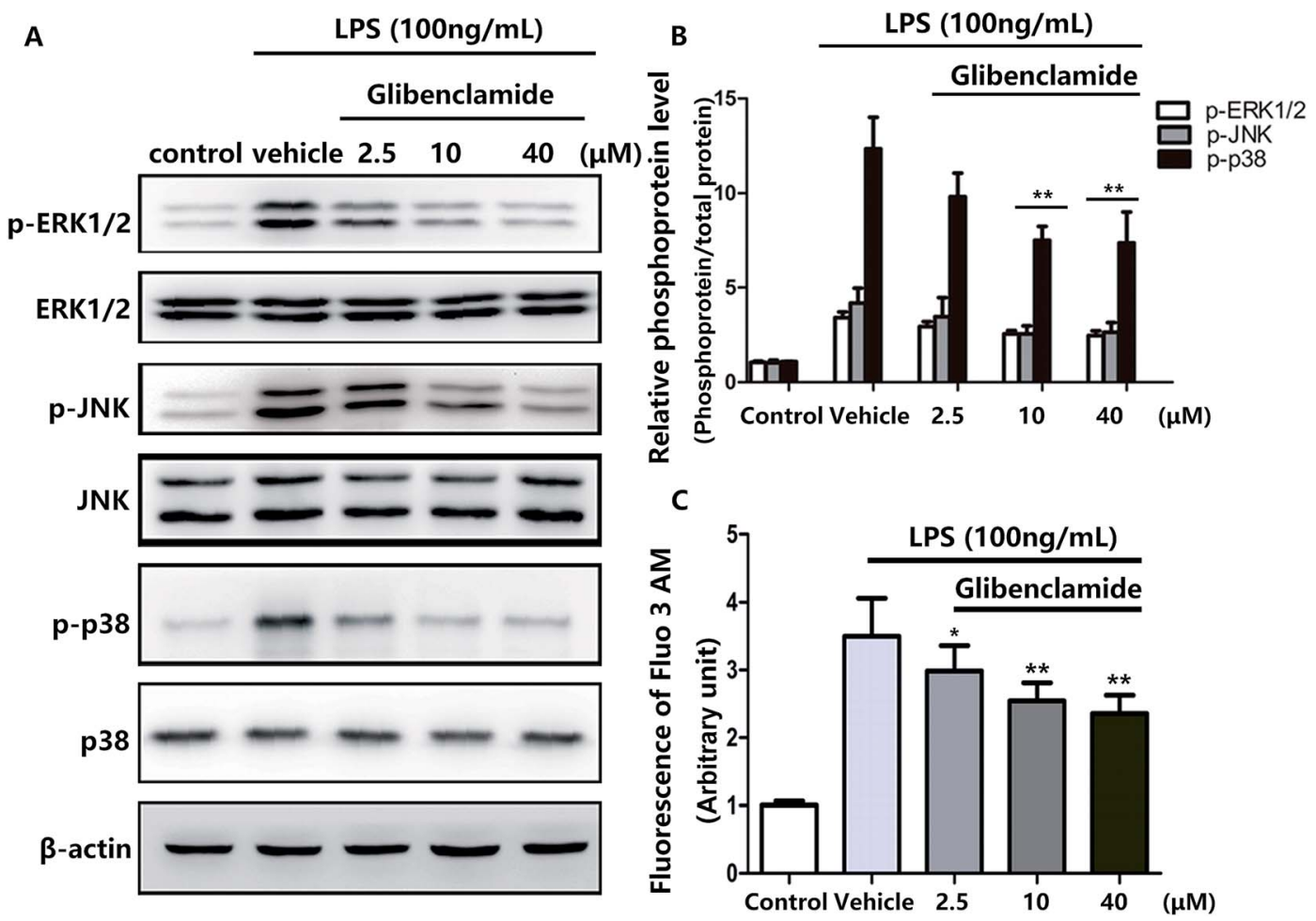

Fig. 4 Glibenclamide attenuated LPS-induced increased concentrations of $\mathrm{Ca}^{2+}$ and phosphorylation of the p38/MAPK pathway in BV2 cells. Phosphorylation of ERK, JNK, and p38 was analyzed (A) and quantified by Western blot analysis (B). Fluo-3 AM levels were quantified with an ELISA plate reader $(C) . * * P<0.01$, vs. with LPS alone.

Three concentrations of glibenclamide were tested, higher concentration $(40 \mu \mathrm{M})$ of glibenclamide did not function better. Glibenclamide was also observed to dose-dependently reduce mRNA levels of proinflammatory cytokines and protein levels of iNOS and COX-2 at concentrations of 2.5 and $10 \mu \mathrm{M}$. Moreover, the three concentrations $(2.5,10$, and $40 \mu \mathrm{M})$ of glibenclamide tested reduced LPS $\left(100 \mathrm{ng} \mathrm{mL}^{-1}\right)$-stimulated microglial cell phosphorylation in the p38/MAPK pathway and the intracellular free calcium ion concentration. Our results are consistent with a report on LPS-induced morphological changes in microglial cells. $^{38}$

It has been reported that blocking Sur1 by glibenclamide not only treats DM II but also reduces cerebral edema caused by hepatic encephalopathy and alleviates intestinal ischemiareperfusion injury. ${ }^{\mathbf{8} 18}$ Recently, studies have indicated that Sur1 mediates cell death in a variety of animal models of diseases, including TBI, SAH, and MS. ${ }^{7,39,40}$ Studies has also indicate that Sur1 plays a pivotal role in neuroinflammation induced by CNS impairment and that glibenclamide can attenuate injury due to an inflammatory reaction. ${ }^{4}$ Sur1 inhibition has also been shown to decrease secondary brain injury in animal models of TBI. ${ }^{41}$ The intracellular calcium concentration influences multiple cellular functions, including enzyme activities; microglia respond to CNS damage by upregulating functions that involve $\mathrm{Ca}^{2+}$ signaling. ${ }^{42}$ Consistent with previous studies, ${ }^{43}$ the present study demonstrated that LPS exposure significantly induced dissociative calcium ions in microglial cells, whereas glibenclamide could abolish LPS- induced increases in free calcium and mRNA levels of proinflammatory cytokines, indicating that glibenclamide's effects on free calcium ions resulting from microglia activation may contribute to its anti-inflammatory actions. It has also been noted that de novo expression of Sur1-regulated NCCa-ATP channels in endothelial cells is important in the temporal and spatial evolution of progressive hemorrhagic necrosis after spinal cord injury. ${ }^{5}$ However, no direct correlation between changes in intracellular $\mathrm{Ca}^{2+}$ concentrations and the antiinflammatory actions of glibenclamide have yet been documented.

The p38/MAPK signaling pathway has been implicated in the development of many neurodegenerative diseases, such as AD, PD and amyotrophic lateral sclerosis (ALS). ${ }^{44,45}$ It has been shown that the production of inflammatory molecules depends partly on the hyperphosphorylation of p38/MAPK pathway components. ${ }^{46}$ Moreover, several studies have shown that the p38/MAPK pathway is an important target for therapeutic drugs intended to control inflammation in the $\mathrm{CNS}^{47,48}$ Recent evidence also suggests that the p38/MAPK pathway regulates microglial responsiveness in TBI. ${ }^{49}$

We found expression of Sur1 along with the BV2 cell activation; glibenclamide significantly attenuated the LPS-induced intracellular $\mathrm{Ca}^{2+}$ concentration in a dose-dependent manner $(2.5,10 \mu \mathrm{M})$. Previous research showed $\mathrm{Ca}^{2+}$-dependent activation of p38/MAPK pathway in several cell types, ${ }^{50,51}$ including immune cells. ${ }^{52-54}$ The recently characterized Sur1-mediated $\mathrm{Ca}^{2+}$ aggregation in LPS-induced BV2 cells can be blocked by 
A

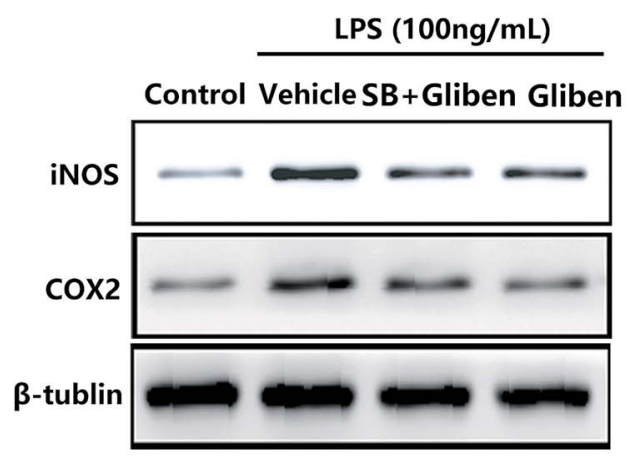

C
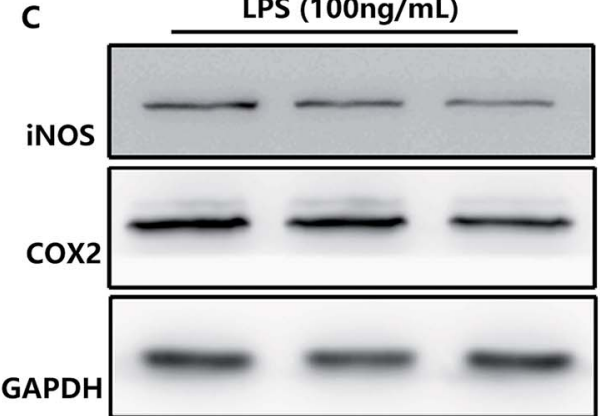

Vehicle

SB203580
(+)

(+)
(+)

(-)

(-)
B

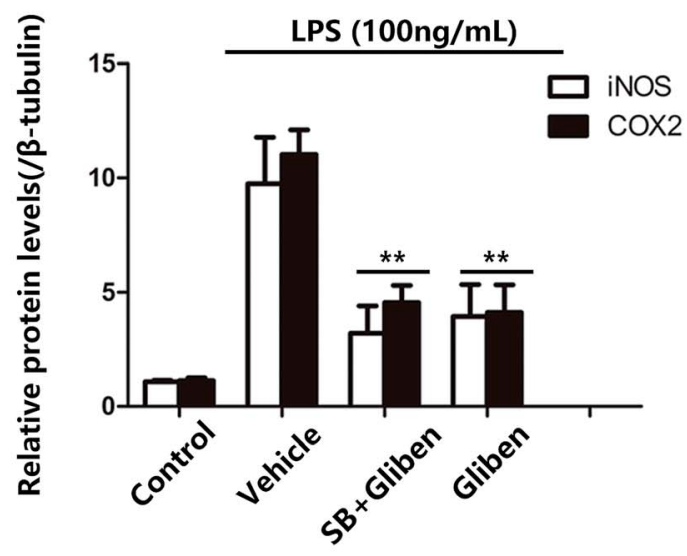

D
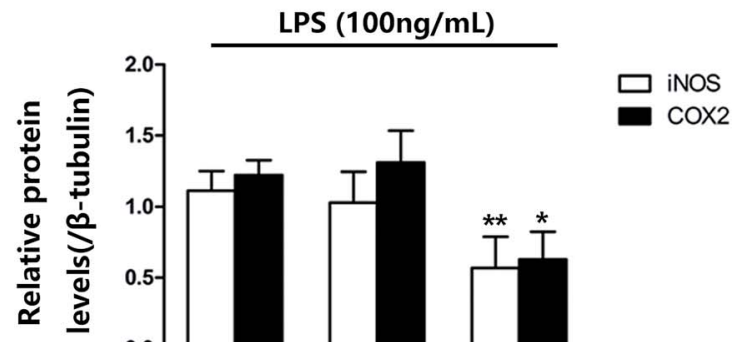

SB203580

Fig. 5 Comparison of the effects of glibenclamide and the p38/MAPK signal pathway inhibitor (SB203580) on LPS-induced inflammatory proteins in BV2 cells. Cells were pre-treated with SB203580 (SB, $10 \mu \mathrm{M}$ ) and glibenclamide (Gliben, $10 \mu \mathrm{M})$ for $1 \mathrm{~h}$ before LPS (100 ng mL ${ }^{-1}$ ) treatment. Level of iNOS and COX-2 proteins were determined by Western blotting (A). Quantification data are shown in (B). Cells were pretreated with SB203580 (10 $\mu \mathrm{M})$ alone for $1 \mathrm{~h}$ before LPS $\left(100 \mathrm{ng} \mathrm{mL}^{-1}\right)$ exposure. Level of iNOS and COX-2 proteins were determined by Western blotting (C). Quantification data are shown in (D). Data represent the mean \pm SEM from three independent experiments. $* P<0.05, * * P<0.01, v S$. the LPS-alone group.

glibenclamide. Thus, calcium overloading leading to p38/MAPK signaling pathway phosphorylation could likely be reduced.

\section{Conclusions}

In conclusion, the results of this study suggest that pretreatment with glibenclamide alleviated the effects of LPSinduced iNOS, and COX-2 protein and cytokine mRNA levels in the progression of microglia BV2 cell activation. Glibenclamide may exhibit anti-inflammatory effects by suppressing LPSinduced production of pro-inflammatory mediators through inhibition of p38 MAPK pathway in BV2 microglial cells.

\section{Acknowledgements}

This work was supported by the National Natural Science Foundation of China (No. 81471245, 81671207, 81501048) and the Shanghai Jiaotong University Medicine-engineering Research Fund (YG2016QN20).

\section{References}

1 S. Seino, Annu. Rev. Physiol., 1999, 61, 337-362.

2 J. Bryan, A. Munoz, X. Zhang, M. Dufer, G. Drews, P. KrippeitDrews and L. Aguilar-Bryan, Eur. J. Appl. Physiol., 2007, 453, 703-718.

3 J. M. Simard, M. Chen, K. V. Tarasov, S. Bhatta, S. Ivanova, L. Melnitchenko, N. Tsymbalyuk, G. A. West and V. Gerzanich, Nat. Med., 2006, 12, 433-440.

4 J. M. Simard, Z. Geng, S. K. Woo, S. Ivanova, C. Tosun, L. Melnichenko and V. Gerzanich, J. Cereb. Blood Flow Metab., 2009, 29, 317-330.

5 J. M. Simard, O. Tsymbalyuk, A. Ivanov, S. Ivanova, S. Bhatta, Z. Geng, S. K. Woo and V. Gerzanich, J. Clin. Invest., 2007, 117, 2105-2113.

6 A. D. Patel, V. Gerzanich, Z. Geng and J. M. Simard, J. Neuropathol. Exp. Neurol., 2010, 69, 1177-1190.

7 B. Schattling, K. Steinbach, E. Thies, M. Kruse, A. Menigoz, F. Ufer, V. Flockerzi, W. Bruck, O. Pongs, R. Vennekens, M. Kneussel, M. Freichel, D. Merkler and M. A. Friese, Nat. Med., 2012, 18, 1805-1811. 
8 K. Pompermayer, F. A. Amaral, C. T. Fagundes, A. T. Vieira, F. Q. Cunha, M. M. Teixeira and D. G. Souza, Eur. J. Pharmacol., 2007, 556, 215-222.

9 K. Zweckberger, C. Eros, R. Zimmermann, S. W. Kim, D. Engel and N. Plesnila, J. Neurotrauma, 2006, 23, 10831093.

10 A. R. Jayakumar, V. Valdes, X. Y. Tong, N. Shamaladevi, W. Gonzalez and M. D. Norenberg, Transl. Stroke Res., 2014, 5, 28-37.

11 N. S. Ningaraj, M. K. Rao and K. L. Black, Cancer Res., 2003, 63, 8899-8911.

12 W. Xia, J. Han, G. Huang and W. Ying, Clin. Exp. Pharmacol. Physiol., 2010, 37, 253-258.

13 Y. Liu, G. Tang, Y. Li, Y. Wang, X. Chen, X. Gu, Z. Zhang, Y. Wang and G. Y. Yang, J. Neuroinflammation, 2014, 11, 177.

14 F. J. Ortega, J. Gimeno-Bayon, J. F. Espinosa-Parrilla, J. L. Carrasco, M. Batlle, M. Pugliese, N. Mahy and M. J. Rodriguez, Exp. Neurol., 2012, 235, 282-296.

15 A. Marble, Drugs, 1971, 1, 109-115.

16 F. M. Ashcroft, Horm. Metab. Res., 1996, 28, 456-463.

17 J. M. Feldman, Am. J. Med., 1985, 79, 102-108.

18 W. Kramer, G. Muller, F. Girbig, U. Gutjahr, S. Kowalewski, D. Hartz and H. D. Summ, Diabetes Res. Clin. Pract., 1995, (28 Suppl), S67-S80.

19 U. Panten, M. Schwanstecher and C. Schwanstecher, Exp. Clin. Endocrinol. Diabetes, 1996, 104, 1-9.

20 C. Tosun, M. T. Koltz, D. B. Kurland, H. Ijaz, M. Gurakar, G. Schwartzbauer, T. Coksaygan, S. Ivanova, V. Gerzanich and J. M. Simard, Brain Sci., 2013, 3, 215-238.

21 E. M. Thompson, G. L. Pishko, L. L. Muldoon and E. A. Neuwelt, Neoplasia, 2013, 15, 535-543.

22 H. Jaeschke, J. Gastroenterol. Hepatol., 2011, 1(26 Suppl), 173-179.

23 T. Uto, N. Suangkaew, O. Morinaga, H. Kariyazono, S. Oiso and Y. Shoyama, Am. J. Chin. Med., 2010, 38, 985-994.

24 J. Da Silva, B. Pierrat, J. L. Mary and W. Lesslauer, J. Biol. Chem., 1997, 272, 28373-28380.

25 G. Pearson, F. Robinson, T. Beers Gibson, B. E. Xu, M. Karandikar, K. Berman and M. H. Cobb, Endocr. Rev., 2001, 22, 153-183.

26 K. M. Rao, J. Leukocyte Biol., 2001, 69, 3-10.

27 N. Rajapakse, M. M. Kim, E. Mendis and S. K. Kim, Immunology, 2008, 123, 348-357.

28 Y. W. Gu, D. S. Su, J. Tian and X. R. Wang, Neurosci. Lett., 2008, 431, 129-134.

29 Z. Y. Zhuang, P. Gerner, C. J. Woolf and R. R. Ji, Pain, 2005, 114, 149-159.

30 Z. Y. Zhuang, Y. R. Wen, D. R. Zhang, T. Borsello, C. Bonny, G. R. Strichartz, I. Decosterd and R. R. Ji, J. Neurosci., 2006, 26, 3551-3560.

31 M. C. Riddle, J. Clin. Endocrinol. Metab., 2003, 88, 528-530.
32 A. Y. Lai and K. G. Todd, Can. J. Physiol. Pharmacol., 2006, 84, 49-59.

33 B. Liao, W. Zhao, D. R. Beers, J. S. Henkel and S. H. Appel, Exp. Neurol., 2012, 237, 147-152.

34 F. Yuan, Z. M. Xu, L. Y. Lu, H. Nie, J. Ding, W. H. Ying and H. L. Tian, J. Neurochem., 2016, 136, 581-593.

35 Y. Li, H. Nie, D. Wu, J. Zhang, X. Wei and W. Ying, Neurosci. Lett., 2013, 544, 36-40.

36 S. Lund, K. V. Christensen, M. Hedtjarn, A. L. Mortensen, H. Hagberg, J. Falsig, H. Hasseldam, A. Schrattenholz, P. Porzgen and M. Leist, J. Neuroimmunol., 2006, 180, 71-87.

37 V. H. Perry, J. A. Nicoll and C. Holmes, Nat. Rev. Neurol., 2010, 6, 193-201.

38 A. Sakai, K. Takasu, M. Sawada and H. Suzuki, PLoS One, 2012, 7, e32268.

39 J. M. Simard, M. Kilbourne, O. Tsymbalyuk, C. Tosun, J. Caridi, S. Ivanova, K. Keledjian, G. Bochicchio and V. Gerzanich, J. Neurotrauma, 2009, 26, 2257-2267.

40 C. Tosun, D. B. Kurland, R. Mehta, R. J. Castellani, J. L. deJong, M. S. Kwon, S. K. Woo, V. Gerzanich and J. M. Simard, Stroke, 2013, 44, 3522-3528.

41 K. Zweckberger, K. Hackenberg, C. S. Jung, D. N. Hertle, K. L. Kiening, A. W. Unterberg and O. W. Sakowitz, Neuroscience, 2014, 272, 199-206.

42 K. Farber and H. Kettenmann, Glia, 2006, 54, 656-665.

43 L. Yuan, S. Liu, X. Bai, Y. Gao, G. Liu, X. Wang, D. Liu, T. Li, A. Hao and Z. Wang, J. Neuroinflammation, 2016, 13, 77.

44 M. Lyman, D. G. Lloyd, X. Ji, M. P. Vizcaychipi and D. Ma, Neurosci. Res., 2014, 79, 1-12.

45 E. K. Kim and E. J. Choi, Biochim. Biophys. Acta, 2010, 1802, 396-405.

46 M. R. Guimaraes, F. R. Leite, L. C. Spolidorio, K. L. Kirkwood and C. Rossa Jr, Arch. Oral Biol., 2013, 58, 1309-1317.

47 D. Gomez-Nicola, B. Valle-Argos and M. Nieto-Sampedro, Glia, 2010, 58, 264-276.

48 S. Saccani, S. Pantano and G. Natoli, Nat. Immunol., 2002, 3, 69-75.

49 A. D. Bachstetter, R. K. Rowe, M. Kaneko, D. Goulding, J. Lifshitz and L. J. Van Eldik, J. Neurosci., 2013, 33, 61436153.

50 P. R. Blanquet, Neuroscience, 2000, 95, 705-719.

51 S. Dehez, L. Daulhac, A. Kowalski-Chauvel, D. Fourmy, L. Pradayrol and C. Seva, FEBS Lett., 2001, 496, 25-30.

52 S. Kreideweiss, C. Ahlers, A. Nordheim and A. Ruhlmann, Eur. J. Biochem., 1999, 265, 1075-1084.

53 D. J. Elzi, A. J. Bjornsen, T. MacKenzie, T. H. Wyman and C. C. Silliman, Am. J. Physiol.: Cell Physiol., 2001, 281, C350-C360.

54 Y. Shigemoto-Mogami, S. Koizumi, M. Tsuda, K. Ohsawa, S. Kohsaka and K. Inoue, J. Neurochem., 2001, 78, 1339-1349. 